\title{
Menopausal-specific quality of life among women in Hong Kong
}

\author{
Cheng LS Winnie \\ School of Nursing \\ Tung Wah College \\ Hong Kong \\ winniecheng@twc.edu.hk
}

\author{
Wong MF Florence \\ School of Nursing \\ Tung Wah College \\ Hong Kong \\ florencewong@twc.edu.hk
}

\begin{abstract}
This study aimed to explore the menopausal-specific quality of life and assess its relationship with the sociodemographic characteristics in menopausal and post-menopausal women in Hong Kong. A cross-sectional survey was conducted with 218 women aged between 45 and 80 or over. The quality of life was assessed by Menopause-Specific Quality of Life Questionnaire $\left(M_{E N Q O L}{ }^{\mathrm{TM}}\right)$. Results showed that the mean scores for vasomotor domain: $2.59 \pm 1.71$; psycho-social domain: $2.77 \pm 1.39$; physical domain: $2.89 \pm 1.23$ and sexual domain $2.60 \pm 1.16$. The physical domain had the highest score in menopausal and post-menopausal women. Univariate analysis demonstrated that younger and less educated working post-menopausal women perceive lower quality of life. Our findings suggest that menopausal-related symptoms affect the quality of life.
\end{abstract}

Keywords - menopausal-specific quality of life; post-menopause; menopause; quality of life

\section{INTRODUCTION}

Women often experience problems or symptoms arise from the normal physiological process - menopause $[1,2,3,4,5,6,7,8$, $9,10,11,12]$. Menopause usually starts at the age of 50 in women The transition usually has three parts: perimenopause, menopause, and post-menopause, during which changes in physical, psychosocial, and sexual condition usually begin with perimenopause and last for years until even after post-menopause [13]. For some women, the menopause-related symptoms during the menopausal transitional period constitute various distresses and disturbances in their lives. That distress and disturbances can disrupt their daily activities and sense of well-being, leading to a decrease in quality of life (QOL) $[6,1,9]$.

The QOL among middle-aged women has become a major health concern around the world. Studies also showed that significant relationship existed between psychological distress and QOL in women with menopause [9]. However, very little information exists about the menopausal-specific QOL among the Hong Kong Chinese menopausal and postmenopausal women. This study, therefore, attempted to explore the menopausalspecific QOL and determine the socio-economic factors related to the QOL among the menopausal and postmenopausal women living in Hong Kong. The findings of this present study can help health care professionals to develop appropriate public health measures to improve the well-being of Hong Kong Chinese menopausal and postmenopausal women.

\section{METHODS}

\section{A. Design and sampling}

The present study employed cross-sectional descriptive survey using a self-reported questionnaire to achieve the research objective. The sample size was estimated based on the total population of women aged over 45 in Hong Kong, which was 1,647,710 [14]. Epi-Info version 7 was used to calculate the sample size. A sample of 196 women was required to achieve $95 \%$ confidence interval with $7 \%$ confidence limits. The study was carried out in a district of Hong Kong-Hung Hom. Convenience sampling was used to recruit the study participants from residents living in the study district. As menopausal changes usually begin several years before the last menstrual period, the inclusion criteria were women aged at or above 45 with ability to respond clearly. Those who had been receiving hormonal therapy and history of cancer were excluded from the study.

\section{B. Data collection}

Data were collected during March and April 2013. Verbal consent was obtained from the women. The questionnaire consisted of two parts. The first part focused on sociodemographic characteristics. The second part of the questionnaire aimed to assess the QOL related to the symptoms derived from menopause. A validated questionnaire, namely MenopauseSpecific QOL Questionnaire (MENQOL ${ }^{\mathrm{TM}}$ ) developed by Hilditch et al. [15] was therefore adopted to solicit the responses from the women in this study. There was a total of 29 items in four domains: vasomotor, psychosocial, physical and sexual. Each item was assessed if present or not-present. If not-present, the women continued with next item. If present, the women was

The study was funded by Takeda Pharmaceuticals (Hong Kong) Limited.

DOI: $10.5176 / 2345-7198 \_5.1 .25$ 
asked to indicate the level of bothersome with a 7-point Likert scale ranging from 0 ; not all bothered, to 6; extremely bothered. For analysis, the score became 1 for "not-present", and 2 for "present" with "not at all bothered" through to 8 for "extremely bothered". The mean of each domain ranged from 1 to 8 . The average of domains means represented the overall questionnaire score.

As the MENQOL ${ }^{\mathrm{TM}}$ was originally developed in English, the version used in this present study was translated into Chinese using forward and backward translation. The translated version was administered by trained interviewers. The internal consistency of the translated version was tested with Cronbach alpha, and was 0.865 .

\section{ETHICAL CONSIDERATIONS}

The Human Research Ethics Committee at the Tung Wah College approved the study protocol. Study information about the research objective and requirements of participants was given to all enrolled women. Verbal consent was obtained from the women, and confidentiality was assured.

\section{DATA ANALYSIS}

Data collected from the questionnaire were coded and analyzed by the Computerized Statistical Package of Social Science, version 23. Descriptive statistics were used to analyze demographic data. Non-parametric tests, Kruskal Wallis and Mann Whitney $U$ tests were used to determine the impact of menopausal symptoms on the QOL. In all statistical analyses, a $p$-value of less than 0.05 was considered as statistical significant.

\section{RESUlts}

Two hundred and twenty-three women responded and completed the questionnaire out of a total of 304 invited women. The response rate was $73.3 \%$. Two hundred and eighteen valid questionnaires were recovered for analysis.

\section{A. Demographic data}

$73.9 \%(n=161)$ of women were aged 50 or older, and most were from 50 to 55 years old $(34.4 \%)$. The majority were married $(79.1 \%)$ and retired or housewives $(44 \%) .62 .4 \%$ of them had Secondary or above education. The majority of women $(63.8 \%)$ had passed menopause (post-menopause), and $36.2 \%$ (pre-menopause) of them were in the transitional period. All pre-menopause women aged below 61. Detailed demographic data are presented in Table I.

\section{B. Menopausal specific quality of life}

Table II shows the median and mean scores of each MENQOL $^{\mathrm{TM}}$ domain. As shown, the mean of physical domain had the highest score, and the sexual domain obtained the lowest score. About forty-three percent of the women obtained vasomotor scores below the median, $48.6 \%$ of the women scored below the median in psycho-social domain, $48.2 \%$ of the women scored below the median in the physical domain, and $45.4 \%$ in the sexual domain scored below the median.

When the median of each domain is compared, physical domain shows the highest median, indicating that physical symptoms affect the QOL among the menopausal and postmenopausal women.

TABLE I. DEMOGRAPHIC DATA

\begin{tabular}{|c|c|c|c|}
\hline & Variables & Number & Percentage \\
\hline Age group & $\begin{array}{l}45-49 \\
\text { Post-menopause } \\
\text { Pre-menopause }\end{array}$ & $\begin{array}{l}57 \\
12 \\
45\end{array}$ & 26.1 \\
\hline & $\begin{array}{l}50-55 \\
\text { Post-menopause } \\
\text { Pre-menopause }\end{array}$ & $\begin{array}{l}75 \\
42 \\
33\end{array}$ & 34.4 \\
\hline & $\begin{array}{l}56-60 \\
\text { Post-menopause } \\
\text { Pre-menopause }\end{array}$ & $\begin{array}{l}28 \\
27 \\
1\end{array}$ & 12.8 \\
\hline & $\begin{array}{l}61-70 \\
\text { Post-menopause } \\
\text { Pre-menopause }\end{array}$ & $\begin{array}{l}31 \\
31 \\
0\end{array}$ & 14.2 \\
\hline & $\begin{array}{l}71-80 \\
\text { Post-menopause } \\
\text { Pre-menopause }\end{array}$ & $\begin{array}{l}16 \\
16 \\
0\end{array}$ & 7.3 \\
\hline & $\begin{array}{l}>80 \\
\text { Post-menopause } \\
\text { Pre-menopause }\end{array}$ & $\begin{array}{l}11 \\
11 \\
0\end{array}$ & 5.0 \\
\hline $\begin{array}{l}\text { Menopausal } \\
\text { phase }\end{array}$ & $\begin{array}{l}\text { Post-menopause } \\
\text { Pre-menopause }\end{array}$ & $\begin{array}{l}139 \\
79\end{array}$ & $\begin{array}{l}63.8 \\
36.2\end{array}$ \\
\hline Occupation & $\begin{array}{l}\text { Management/ } \\
\text { Professional } \\
\text { Executive } \\
\text { General } \\
\text { Retired/Housewife } \\
\text { Unemployment/ } \\
\text { Volunteer }\end{array}$ & $\begin{array}{l}15 \\
7 \\
45 \\
96 \\
10\end{array}$ & $\begin{array}{l}6.9 \\
\\
3.2 \\
20.6 \\
44.0 \\
4.6\end{array}$ \\
\hline Income & $\begin{array}{l}<10,000 \\
10,000-30,000 \\
30,001-50,000 \\
>50,000 \\
\text { Unknown }\end{array}$ & $\begin{array}{l}47 \\
86 \\
32 \\
18 \\
37\end{array}$ & $\begin{array}{l}21.6 \\
39.4 \\
14.7 \\
8.3 \\
16.1\end{array}$ \\
\hline $\begin{array}{l}\text { Marital } \\
\text { status }\end{array}$ & $\begin{array}{l}\text { Unmarried } \\
\text { Married }\end{array}$ & $\begin{array}{l}48 \\
170\end{array}$ & $\begin{array}{l}20.9 \\
79.1\end{array}$ \\
\hline $\begin{array}{l}\text { Educational } \\
\text { level }\end{array}$ & $\begin{array}{l}\text { None and below } \\
\text { primary } \\
\text { Primary } \\
\text { Secondary } \\
\text { University } \\
\text { degree or above }\end{array}$ & $\begin{array}{l}32 \\
50 \\
100 \\
36\end{array}$ & $\begin{array}{l}14.7 \\
\\
22.9 \\
45.9 \\
16.5\end{array}$ \\
\hline
\end{tabular}


TABLE II. MEDIAN AND MEAN SCORES PER DOMAIN AND OVERALL QOL OF MENQOL ${ }^{\mathrm{TM}}$

\begin{tabular}{llllc}
\hline Domain & Median & Mean & $\begin{array}{c}\text { Standard } \\
\text { deviation }\end{array}$ & $\begin{array}{c}95 \% \\
\text { Confidence } \\
\text { interval }\end{array}$ \\
\hline Vasomotor & 2 & 2.59 & 1.71 & $2.36-2.82$ \\
Psycho-social & 2.57 & 2.77 & 1.39 & $2.58-2.57$ \\
Physical & 2.75 & 2.89 & 1.23 & $2.73-3.05$ \\
Sexual & 1.33 & 2.17 & 1.62 & $1.95-2.39$ \\
Overall QOL & 2.41 & 2.60 & 1.16 & $2.45-2.76$ \\
& & & &
\end{tabular}

\section{Factors related to menopausal symptoms}

Table III reports the mean scores of the four domains of the MENQOL $^{\mathrm{TM}}$ at different socio-demographic characteristics. In the four domains of the MENQOL ${ }^{\mathrm{TM}}$, the women aged 56 to 60 reported the worst MENQOL ${ }^{\mathrm{TM}}$ scores significantly, except for psycho-social domain. The post-menopausal women reported significantly higher scores in the physical and sexual domains; meaning a decrease in QOL. There were no significant differences between various occupations in vasomotor, physical, physical domains, except for sexual domain. Women working as general workers had significant impaired QOL in sexual domain.

There were no significant differences among women with different family income and marital status in all domains.

Educational level was related to the physical domain. The women with university degree or above obtained a lower score, indicating an improvement in QOL.

\section{DISCUSSION}

The purpose of this present study aimed to explore the menopausal-specific QOL using $\mathrm{MENQOL}^{\mathrm{TM}}$ and its related socio-economic factors among the menopausal and postmenopausal women living in Hong Kong.

Based on the findings, the physical symptoms had the highest score; indicating impaired QOL was found in this population. Muscle and joint pain and feeling tired were the most common symptoms reported by the women. Previous studies also showed that muscle and joint problems $[5,10,12,16,17,18]$ and feeling tired $[3,8]$ were frequently reported by menopausal women. One must be noted that the mean score in the physical domain $(2.89 \pm$ 1.23) among the menopausal and post-menopausal women in Hong Kong was higher than that of some overseas counterparts, who had a comparatively lower mean score (1.22 $\pm 0.96-1.91 \pm$ $0.52)[10,17]$; meaning that the problem of physical symptoms were more serious among the menopausal and post-menopausal women in Hong Kong. Further research is needed in this area.
TABLE III. ADJUSTED MEAN SCORES PER DOMAIN ACCORDING TO SOCIODEMOGRAPHIC CHARACTERISTICS

\begin{tabular}{lllll}
\hline & \multicolumn{3}{l}{ Domain } \\
\hline Characteristics & Vasomotor $^{a}$ & $\begin{array}{l}\text { Psycho- } \text { social }^{a} \\
\text { Age group }\end{array}$ & Physical $^{a}$ & Sexual $^{a}$ \\
$45-49$ & $2.35(1.81)$ & $2.46(1.29)$ & $2.47(1.12)$ & $1.78(1.47)$ \\
$50-55$ & $2.97(1.74)$ & $2.99(1.47)$ & $3.03(1.14)$ & $2.50(1.80)$ \\
$56-60$ & $3.42(1.76)$ & $3.29(1.69)$ & $3.47(1.40)$ & $2.98(1.98)$ \\
$61-70$ & $2.08(1.16)$ & $2.44(1.15)$ & $2.84(1.29)$ & $1.77(1.11)$ \\
$71-80$ & $1.90(1.48)$ & $2.70(1.12)$ & $3.01(1.18)$ & $1.79(1.02)$ \\
$>80$ & $1.61(1.04)$ & $2.57(1.01)$ & $2.62(1.25)$ & $1.55(0.73)$ \\
p-value $^{\mathrm{b}}$ & $<0.001$ & 0.115 & 0.014 & 0.001
\end{tabular}

\section{Menopausal status}

Pre-menopuase

$2.49(1.78)$

$2.68(1.36)$

$2.55(1.15)$

$1.83(1.41)$

Post-menopause

$2.65(1.67)$

$2.82(1.41)$

$3.08(1.23)$

$2.37(1.70)$

p-value

0.302

0.485

0.002

0.001

\section{Occupation}

Managemen

/Professional

Executive

$1.87(1.28)$

$2.10(0.96)$

$2.63(1.05)$

$2.29(1.84)$

1.95 (1.72)

$2.41(1.17)$

$2.30(0.49)$

$1.00(0.00)$

General worker

$2.73(1.79)$

$2.87(1.38)$

$2.91(1.22)$

$2.55(1.95)$

Retired/Housewife

2.63 (1.64)

$2.75(1.41)$

2.78 (1.19)

$1.92(1.36)$

Unemployment/

Volunteer

p-value

$1.73(1.39)$

$2.93(1.63)$

$3.10(1.53)$

$2.35(1.68)$

0.095

0.425

0.696

0.034

\section{Family income}

$<10,000$

$2.26(1.45)$

2.75 (1.46)

2.86 (1.33)

$2.18(1.74)$

$10,000-30,000$

$2.94(1.81)$

$2.99(1.30)$

$3.00(1.12)$

$2.22(1.74)$

$30,001-50,000$

$>50,000$

p-value

$2.33(1.66)$

$2.71(1.68)$

$3.02(1.39)$

$2.54(1.61)$

$2.81(2.11)$

$2.65(1.39)$

$2.80(1.12)$

1.97 (1.30)

0.132

0.429

0.815

0.438

\section{Marital status}

Unmarried

$2.33(1.69)$

$2.66(1.34)$

$2.71(1.31)$

$2.11(1.66)$

Married

p-value

$2.66(1.71)$

$2.80(1.40)$

$2.94(1.20)$

$2.18(1.62)$

0.144

0.618

0.218

0.811

\section{Education}

None and below

primary

Primary

Secondary

University degree

or above

p-value ${ }^{b}$
$2.09(1.30)$

$2.96(1.77)$

$2.46(1.49)$

$2.44(2.08)$

0.141
$2.64(1.23)$

$2.68(1.22)$

$1.42(0.77)$

$3.04(1.41) \quad 3.16(1.28)$

$2.16(1.62)$

$2.84(1.35)$

$2.97(1.20)$

$2.78(1.61)$

$2.32(1.20)$

$2.43(0.92)$

$2.29(1.85)$

0.107

0.033

0.210 
In this study, older women had better QOL. This finding was consistent with previous studies [10, 16, 19]. It may be explained by their coping behavior developed toward the menopausal symptoms over time. More often than not, QOL was evaluated in menopausal and post-menopausal women aged between 45 and 65 in similar studies $[1,9,10,20]$; this study examined the QOL among women aged beyond 65 to 80 and above. This study sheds light on the QOL of this population. Though older women had a better QOL, their physical symptoms deserve attention because the score in this domain was comparatively high in women aged 71- 80 .

In general, younger and less educated post-menopausal women experienced a lower QOL on many of the MENQOL ${ }^{\mathrm{TM}}$ domains. Women aged 50-60 experienced the worse QOL due to their physical, vasomotor, physical and sexual symptoms in the menopausal transition period. The retirement age is 60 for most organizations in public and private sectors in Hong Kong. This negative menopausal experience couples with the psychological burden that might be faced by women in the process of preparing their retirement may further impair their QOL. This information is noteworthy for health and social care professionals who support women approaching their retirement age.

In this study, the younger post-menopausal women with employment had a higher score in the sexual domain than the nonworking women. Women with dual roles perceived worse QOL. This finding is consistent with previous study [1].

Women with higher education perceived better QOL in the physical domain. This finding is consistent with previous studies $[10,20,21,22]$. It is likely that women with better education will be more likely to have increased health literacy to access relevant health information and therefore better coping strategies were developed. Interestingly, the QOL does not relate to family income in this study population. It may be due to the Hong Kong citizens have an equitable access to the affordable public health care service.

Several limitations of this study must be noted. Firstly, this cross-sectional study could not assess the change in menopausal symptoms with time. The women in this study were recruited from a single district could not necessarily represent the characteristics of the Hong Kong population as a whole. Past history of illness was not assessed except breast cancer, among the women in this study; it warrants consideration when interpreting some of the reported symptoms that might be affected by the comorbid diseases.

\section{CONCLUSIONS}

The present study suggests that physical symptoms affect the QOL among the menopausal and post-menopausal women in Hong Kong. Further study is recommended to confirm the results Such regional study also highlights that socio-demographic characteristics are associated with menopausal-specific QOL and thus can help identify strategies and education to improve the QOL.

\section{ACKNOWLEDGMENTS}

The researchers would like to thank the women who participated in this study and the colleagues who helped collected the information from the participants.

\section{REFERENCES}

[1] G K. Poomalar, and B. Arounassalame, "The quality of life during and after menopause among rural women," Journal of Clinical and Diagnostic Research, vol. 7(1), pp.135-139, January 2013.

[2] R. Y. Abdelrahman, L. A. Abushaikha, and M.A. al-Motlaq, "Predictors of psychological well-being and stress among Jordanian menopausa women," Quality of Life Research, vol. 23(1), pp.167-173, February 2014.

[3] K. Ahmed, P. Jahan, I. Nadia, F. Ahmed, and Abdullah-Al-Emran, "Assessment of Menopausal Symptoms among Early and Late Menopausal Midlife Bangladeshi Women and Their Impact on the Quality of Life," Journal of Menopausal Medicine, vol. 22(1), pp.39-46, April 2016.

[4] B. Ayers, M. Hunter, "Health-related quality of life of women with menopausal hot flushes and night sweats," Climacteric, vol.16(2), pp.235239, April 2013.

[5] M. Chou, Y. Wun, and S. Pang, "Menopausal symptoms and the Menopausal Rating Scale among midlife Chinese women in Macau, China," Women \& Health, vol. 54(2), pp.115-126, February 2014.

[6] B. Craig, and S. Mitchell, "Examining the Value of Menopausal Symptom Relief among US Women," Value in Health, vol. 19(2), pp.158-166, March 2016

[7] D. Ling, W. Wong, and S. Ho, "Are post-menopausal women "half-aman"?: sexual beliefs, attitudes and concerns among midlife Chinese women," Journal of Sex \& Marital Therapy, vol. 34(1), pp.15-29, 2008.

[8] J. Lu, J. Liu, and J. Eden, "The experience of menopausal symptoms by Arabic women in Sydney," Climacteric, vol. 10(1), pp.72-79, February 2007

[9] A. Masood, S. Rashid, R. Musarrat, and S. Mazahir, "Depression, anxiety, psychological distress and quality of life of women in menopausal phase,” Pakistan Journal of Women's Studies, vol. 23(1), pp.77-89, January 2016.

[10] S. Mirhaghjou, M. Niknami, M, Moridi, S. Pakseresht, and E. Kazemnejad, "Quality of life and its determinants in postmenopausal women: a population-based study," Applied Nursing Research, vol. 30, pp.252-256, May 2016.

[11] M. Sussman, J. Trocio, and M, Louie, et al., "Prevalence of menopausa symptoms among mid-life women: findings from electronic medical records," BMC Women's Health, vol.15, pp.58, August 2015.

[12] J. Whiteley, M. DiBonaventura, J. Wagner, J. Alvir, and S. Shah, "The Impact of Menopausal Symptoms on Quality of Life, Productivity, and Economic Outcomes," Journal of Women's Health, vol. 22(11), pp.983990, November 2013.

[13] M. Lock, and V. K. Nguyen, An Anthropology of Biomedicine. Oxford: Wiley-Blackwell. 2010

[14] Census and Statistics Department. 2016. The Government of the HKSAR (Retrieved from http://www.census2011.gov.hk/en/census-result.html)

[15] J. R. Hilditch, J. Lewis, A. Peter, B. van Maris, A. Ross, and E. Franssen, et al., "A menopause-specific quality of life questionnaire: Development and psychometric properties," Maturitas, vol.24(3), pp.161-175, 1996.

[16] P. Chedraui, F, Pérez-López, L. Hidalgo, et al., "Severe menopausal symptoms in middle-aged women are associated to female and male factors," Archives of Gynecology \& Obstetrics, vol.281(5), pp.879-885, September 2010.

[17] M. Ghazanfarpour, M. Kaviani, and T. Khadivzadeh, et al., "The relationship between women's attitude towards menopause and menopausa symptoms among postmenopausal women," Gynecological Endocrinology, vol.31(11), pp.860-865, 2015 
[18] D. Yang, C. Haines, and W. Liao, et al., "Menopausal symptoms in midlife women in Southern China," Climacteric, vol. 11(4), pp.329-336, August 2008.

[19] P. A. Jacobs, M. E. Hyland, and A. Ley, "Self-rated menopausal status and quality of life in women aged 40-63 years," British Journal of Health Psychology, vol. 5(4), pp.396-411, 2000.

[20] A. Calvo-Pérez, and C. Campillo-Artero, "Quality of life of menopausal women in the island of Majorca: a population based study," Gynecological Endocrinology, vol. 29(6), pp.556-558, June 2013.

[21] H. Fallahzadeh, "Quality of life after the menopause in Iran: A population study," Quality of Life Research, vol. 19(6), pp. 813-819. 2010.

[22] R. E. Williams, K. B. Levine, L. Kalilani, J. Lewis, and R. V. Clark "Menopause-specific questionnaire assessment in US population-based study shows negative impact on health-related quality of life," Maturitas, vol. 62(2), pp.153-159, February 2009. 